\title{
Coriocarcinoma primário do colo uterino
}

\author{
Primary choriocarcinoma of the uterine cervix
}

\section{Maria Fernanda Moreira Ferraz ${ }^{1}$ \\ Gisele Alborghetti Nai ${ }^{2}$ \\ Suzete Motta Peretti $\left.\right|^{3}$}

\begin{tabular}{|c|c|}
\hline unitermos & resumo \\
\hline $\begin{array}{l}\text { Doença trofoblástica } \\
\text { gestacional } \\
\text { Coriocarcinoma } \\
\text { Colo uterino }\end{array}$ & $\begin{array}{l}\text { Coriocarcinomas geralmente ocorrem no corpo uterino durante o período reprodutivo. } \\
\text { Raramente podem acontecer alterações de localização e de idade de acometimento. } \\
\text { Coriocarcinomas primários do colo uterino são extremamente raros, geralmente ocorrem } \\
\text { no pós-parto de seis meses a dois anos e se apresentam com sangramento por via vaginal. } \\
\text { Existem três teorias para o desenvolvimento dos coriocarcinomas no colo uterino: } \\
\text { 1) a paciente ter tido uma gestação cervical que sofreu transformação maligna; } 2 \text { ) que o } \\
\text { coriocarcinoma da cérvice seja uma metástase de um tumor primário do corpo que } \\
\text { desapareceu; } 3 \text { ) que seu desenvolvimento seja devido ao transporte de células coriônicas } \\
\text { da gestação precedente como êmbolos, os quais ficaram latentes e posteriormente sofreram } \\
\text { transformação maligna. A terapêutica preconizada é a realização de histerectomia com } \\
\text { manutenção dos anexos e posterior quimioterapia. Relatamos o caso de uma mulher de } 34 \\
\text { anos que, seis meses após parto normal, iniciou com sangramento vaginal. O exame } \\
\text { especular mostrou massa vegetante e hemorrágica do colo uterino e a dosagem de } \\
\text { gonadotrofina coriônica humana fração } \beta \text { ( } \beta \text {-HCG) revelou altos níveis sangüíneos. O exame } \\
\text { histopatológico mostrou uma neoplasia maligna composta por sincício e citotrofoblasto } \\
\text { malignos comprometendo apenas o colo uterino. Nosso caso é um coriocarcinoma ectópico } \\
\text { e acreditamos que seu desenvolvimento no colo uterino seja devido ao transporte de células } \\
\text { coriônicas da gravidez precedente que sofreram posterior transformação maligna. }\end{array}$ \\
\hline
\end{tabular}

\section{abstract}

Choriocarcinomas usually occur within the body of the uterus during reproductive years. On rare occasions they may occur abnormally in relation to place and time. Primary choriocarcinomas of the uterine cervix are extremely rare. They usually occur in a latent period of six months to two years after the preceding pregnancy, and present with disfunctional vaginal bleeding. Theoretically, there are three mechanisms for the development of the cervical choriocarcinoma:

1) the patient initially had a cervical pregnancy and this was followed by malignant transformation; 2) the cervical choriocarcinoma may be a metastasis from the primary tumor of the corpus, which had disappeared; 3 ) the development of cervical choriocarcinoma was due to the transport of chorionic cells from the preceding pregnancy as emboli, which stayed dormant and, later, gave rise to malignant transformation. Total abdominal histerectomy and posterior chemotherapy are recommended. We report a case of a 34 -year-old woman, with vaginal bleeding six months after a term pregnancy, which had a hemorrhagic cervical mass and high

$\beta$-HCG blood levels. The histopathology showed a tumor with a malignant sincicio and citotrophoblastic components involving only the uterine cervix. Our case is one of an ectopic choriocarcinoma and we believe that its development is due to the transport of chorionic cells from the preceding pregnancy and later gave rise to malignant transformation.

key words

Gestational trophoblastic disease

Choriocarcinoma Uterine cervix
1. Mestre; professora assistente do Departamento de Ginecologia e Obstetrícia da Faculdade de Medicina da Universidade do Oeste Paulista (Unoeste).

2. Médica patologista; professora assistente do Departamento de Patologia da Faculdade de Medicina da Unoeste.

3. Médica ginecologista; professora assistente do Departamento de Anatomia Humana da Faculdade de Medicina da Unoeste. 


\section{Introducão}

O coriocarcinoma representa a lesão mais maligna das doenças trofoblásticas gestacionais (2) e pode aparecer em qualquer tipo de gestação, sendo que $50 \%$ se apresentam após uma mola hidatiforme, $25 \%$ provêm de abortos espontâneos, $22,5 \%$ de gestações de mais de 28 semanas e $2,5 \%$ de gestações ectópicas $(3,8)$.

O colo uterino é um local extremamente incomum para coriocarcinomas ectópicos. Isto é evidente quando se considera a raridade de gravidez cervical. Com a taxa de doença trofoblástica de 1/2.000 gestações e de coriocarcinomas de 1/50.000 nascimentos, a rara combinação de coriocarcinoma e colo uterino tornase mais aparente $(2,4,5)$.

Relatamos um caso de coriocarcinoma primário do colo uterino após seis meses de uma gestação a termo e discutimos as prováveis teorias de seu aparecimento.

\section{Relato do caso}

Mulher de 34 anos com história de gestação a termo e parto vaginal há seis meses. Há um mês começou a apresentar sangramento via vaginal abundante. O exame especular mostrou uma tumoração exofítica, hemorrágica, comprometendo todo o colo uterino.

A paciente foi submetida a histerectomia e, durante $o$ ato operatório, observaram-se linfoadenomegalias em toda a cadeia paraaórtica, ilíaca e inguinal.

A dosagem de sangüínea de $\beta$-HCG no primeiro pós-operatório era extremamente elevada.

\section{Exame anatomopatológico}

O útero foi enviado seccionado longitudinalmente, media $8,5 \mathrm{~cm} \times 5,5 \mathrm{~cm} \times 3 \mathrm{~cm}$ e pesava $53 \mathrm{~g}$. Apresentava massa vegetante, hemorrágica, friável no colo uterino, infiltrando sua parede e parte do canal cervical, medindo $4,5 \mathrm{~cm} \times 3,5 \mathrm{~cm} \times 2 \mathrm{~cm}$ (Figura 1).

O endométrio e o miométrio não apresentavam alterações dignas de nota.

Foi enviada, também, massa identificada como linfonodo inguinal, medindo $7,5 \mathrm{~cm} \times 4,5 \mathrm{~cm} \times 2 \mathrm{~cm}$, revestido por cápsula lisa e brilhante e que, aos cortes, tinha coloração creme, consistência macia e focos de hemorragia e necrose.

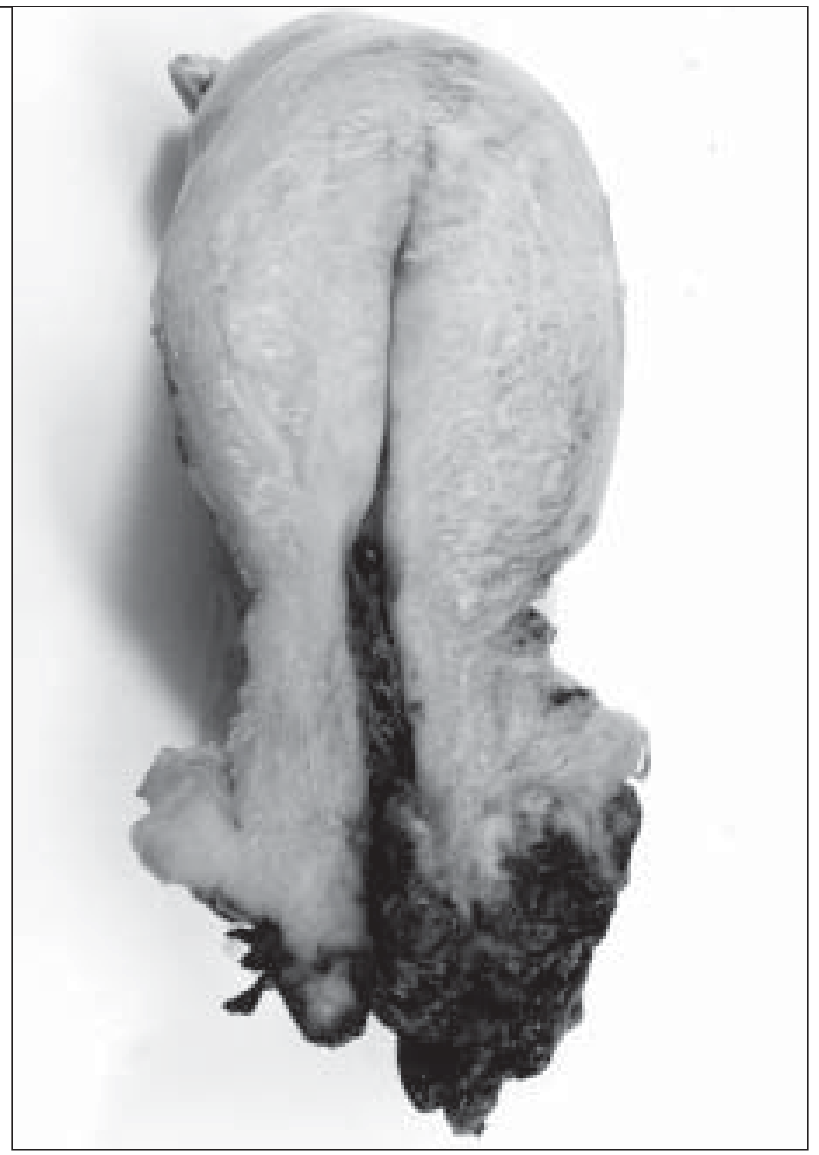

Figura 1 - Corte longitudinal do útero, mostrando massa vegetante e hemorrágica comprometendo o colo uterino

Microscopicamente, a neoplasia do colo uterino apresenta componentes de sincício e citotrofoblasto malignos, o primeiro caracterizado por células com citoplasma amplo e multinucleadas e o segundo por células com citoplasma menor e núcleos volumosos, apresentando nucléolos proeminentes e numerosas figuras de mitose atípicas, que infiltram a ectocérvice e permeiam e destroem as glândulas endocervicais (Figuras 2A e 2B).

O miométrio e o endométrio não apresentam comprometimento neoplásico.

Os cortes histológicos da massa inguinal mostram rima de tecido linfóide e extenso comprometimento pela neoplasia descrita acima.

Desta forma estabeleceu-se o diagnóstico de coriocarcinoma primário do colo uterino com metástases para linfonodos abdominais e inguinais.

\section{Discussão}

Coriocarcinomas são classificados em gestacionais e não-gestacionais (teratomatosos) com base em sua origem histogenética. Os coriocarcinomas gestacionais se- 


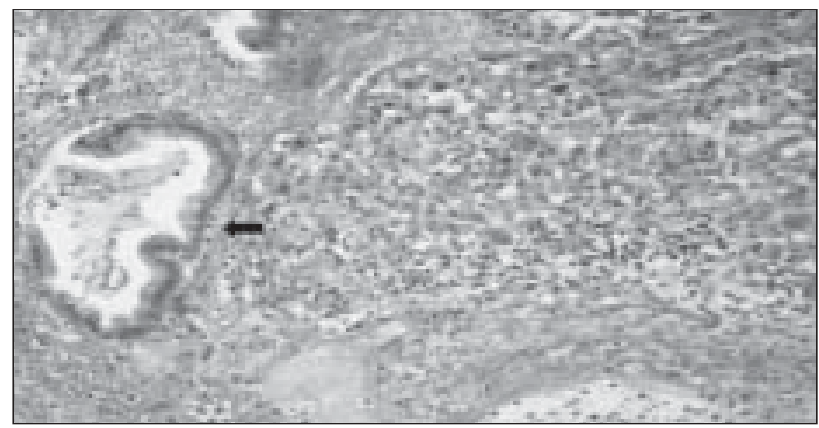

Figura 2A - Neoplasia maligna infiltrando as glândulas endocervicais (seta) (hematoxilina-eosina, 100x)

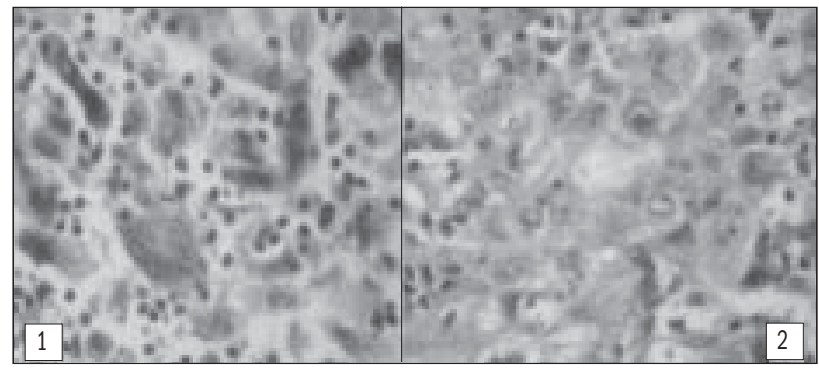

Figura 2B - Detalhes da micrografia anterior mostrando os componentes de sincício (1) e citotrofoblasto (2) malignos (hematoxilina-eosina, 400x)

guem algum tipo de gestação, e os não-gestacionais geralmente derivam do ovário, do testículo, do pulmão, do mediastino e da base do crânio, antes do período de maturidade $(6,7)$.

Coriocarcinomas podem ainda ser heterocrônicos e heterotópicos (ectópicos). Heterocrônico, quando o período de latência de seu aparecimento pós-gestacional é de mais de dois anos (6).

Em 1965, Saito et al. definiram os critérios para coriocarcinomas ectópicos, como se segue: 1) não haver foco primário de coriocarcinoma no corpo uterino; 2) o diagnóstico histopatológico deve confirmar o diagnóstico de coriocarcinoma; 3) devem ser excluídos casos de coriocarcinoma extra-uterinos coexistentes com mola hidatiforme ou gestação intra-uterina normal; 4) coriocarcinomas intramurais do corpo uterino não devem ser considerados ectópicos (6).

Coriocarcinomas do colo uterino são extremamente raros. A literatura mostra um predomínio de casos no Oriente, principalmente no Japão, onde já foram relatados mais de 40 casos $(1,6)$, não havendo relatos de casos na América Latina e no Brasil.

Nosso caso não representa um coriocarcinoma nãogestacional, pois não foram observados, ao exame histopatológico, componentes teratomatosos. Este fato e a história obstétrica da paciente favorecem o diagnóstico de coriocarcinoma gestacional.
Este também preenche todos critérios para classificação entre os grupos ectópicos.

Existem três teorias para o desenvolvimento dos coriocarcinomas no colo uterino: 1) a paciente ter tido uma gestação cervical que sofreu transformação maligna; 2) que o coriocarcinoma da cérvice seja uma metástase de um tumor primário do corpo que desapareceu; 3) que seu desenvolvimento seja devido ao transporte de células coriônicas da gestação precedente como êmbolos, os quais ficaram latentes e posteriormente sofreram transformação maligna (4-6).

Analisando os dados de história e achados clinicopatológicos, favorecemos a terceira teoria para o desenvolvimento do coriocarcinoma do colo uterino em nossa paciente.

O diagnóstico clínico do coriocarcinoma do colo uterino é difícil de ser feito. $\mathrm{O}$ sintoma predominante é sangramento por via vaginal anormal $(4,7)$. A ressonância magnética e o ultra-som transvaginal com doppler colorido podem ser úteis no diagnóstico por identificarem o coriocarcinoma do colo uterino como uma lesão hipervascularizada (7).

Alguns autores defendem que os coriocarcinomas do colo uterino têm uma baixa incidência de metástases e que o seu prognóstico é melhor que o de outros coriocarcinomas ectópicos (6). As metástases geralmente ocorrem para o cérebro e o fígado em $20 \%$ a $60 \%$ dos casos e, ocasionalmente, para os linfonodos.

Estão indicadas histerectomia, apesar de $27 \%$ das pacientes já apresentarem metástases no momento do diagnóstico, e posterior quimioterapia (4).

A presença de coriocarcinoma pós-parto é considerada de alto risco para desenvolvimento de resistência à quimioterapia, entretanto alguns autores enfocam que somente este fator isolado não deve ser considerado mau prognóstico (8).

Nossa paciente apresentava metástases somente para linfonodos das cadeias paraaórtica, ilíaca e inguinal no momento do diagnóstico. Após a cirurgia, foi indicada quimioterapia, mas a paciente perdeu o seguimento, não tendo realizado nenhum ciclo deste tratamento.

Embora extremamente raro, o coriocarcinoma do colo uterino deve ser lembrado como diagnóstico diferencial das patologias deste local.

\section{Agradecimentos}

Ao dr. Marcello F. Franco, pela revisão do caso. 


\section{Referências}

1. Heyn, M. et al. Choriokarzinom der cervix uteri und zevikale schwangerschaft. Geburtsh. U. Frauenheilk. , 53:498-500, 1993.

2. Horn, L.C . et al. Postpartal gestational choriocarcinoma fatally misdiagno sed as squamo us cell cancer of the uterine cer vix. Gen. Diagn. Pathol., 143: 191-6, 1997.

3. Hott, H.A. et al. Coriocarcinoma gestacional en un embarazo tubario. Rev. Chil. Obstet. Ginecol., 58(6): 475-6, 1993.

4. Martin III, B.R. et al. Cervical choriocarcinoma associated with intrauterine contraceptive device: a case report.Am.J. Obstet. Gynecol., 1: 343-4, 1983.
5. Tripathi, R. et al. Choriocarcinoma of cervix. Case report. British Journal of Obstetrics and Gynecology, 89:267-9, 1982.

6. Tsukamoto, N . et al. Primary cervical choriocarcinoma. Gynecology Oncology, 9: 99-107, 1980.

7. Yahata, T. et al. Primary choriocarcinoma of uterine cervix: clinical, MRI, and color doppler ultrasonographic study. Gynecology Oncoidentificadalogy, 64: 274-8, 1997.

8. Zapata, L. et al. Coriocarcinoma posparto. Comunicación de un caso. Rev. Obstet. Ginecol.Venez., 58(1): 49-52, 1998. 